\section{Biliary Obstruction Caused by a Multifocal Duodenal Neurosarcoma in a Patient with von Recklinghausen's Disease}

A 56-year-old man with von Recklinghausen's disease presented with a six-month history of recurrent epigastric pain. The physical examination revealed multiple cutaneous neurofibromas and moderate jaundice (bilirubin: $2.1 \mathrm{mg} / \mathrm{dl}$ ). All tumor markers, including CA19-9 and CEA, were in the normal range. Sonography and CT showed a lesion of $3 \mathrm{~cm}$ in diameter in the head of the pancreas, as well as dilation of the common bile duct to $1.3 \mathrm{~cm}$, raising a suspicion of pancreatic cancer. Panendoscopy, including esophagogastroduodenoscopy and colonoscopy, failed to identify any pathology within the gastrointestinal tract. In particular, no gastrointestinal manifestation of neurofibromatosis or infiltration of the duodenum by a pancreatic tumor was found. Endoscopic retrograde cholangiopancreatography demonstrated a dilation of the extrahepatic bile ducts and a prepapillary stenosis of the common bile duct (Figure 1). There was no evidence of infiltration of the main bile duct or the pancreatic duct by a pancreatic carcinoma. However, endosonography $(7.5 \mathrm{MHz}$ curved-array) displayed an echo-poor tumor of $3 \mathrm{~cm}$ in size, growing submucosally within the duodenal wall. The lesion was well demarcated from the head of the pancreas, but was causing biliary obstruction by compressing the common bile duct (Figure 2). Although no penetration of the duodenal wall was evident on sonography, the tumor was suspicious for malignancy due to its nonhomogeneous echo pattern. The patient underwent laparotomy for resection of the lesion. Intraoperatively, in addition to the lesion in the duodenal wall, two further small nodules were identified in the proximal jejunum, all of which were removed by wedge resection. The histopathology revealed malignant schwannoma in all of the lesions (Figure 3).

Involvement of the gastrointestinal tract in neurofibromatosis is well recognized (1). Malignant transformation of neurinomas in the gastrointestinal tract is exceedingly rare, although an increased incidence of malignancy of up to $15 \%$ has been described for patients with neurofibromatosis (2). Only sporadic reports exist on malignant schwannoma of the small intestine $(3,4)$. The treatment of choice is surgical resection (5). In this case, we found a multifocal malignant schwannoma on the basis of neurofibromatosis

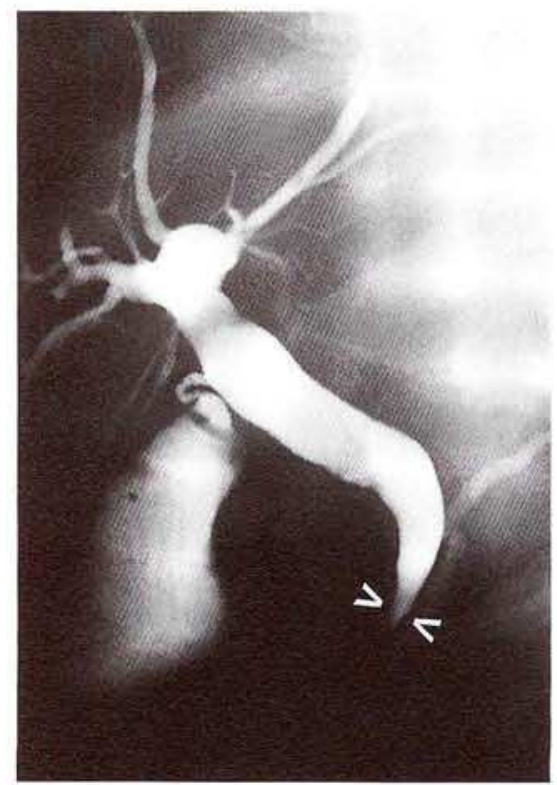

Figure 1: ERCP demonstrates a smooth prepapillary stenosis (arrows) of the common bile duct, with dilation of the extrahepatic bile ducts. causing biliary obstruction. This rare presentation emphasizes the need for careful evaluation of the gastrointestinal tract, including endosonography, in patients with von Recklinghausen's disease who develop symptoms. After a two-year follow-up, the patient is healthy and has no evidence of recurrence.

\section{Hünerbein, M. Dohmoto, W. Haensch, P. M. Schlag}

Dept. of Surgery, Robert Rössle Hospital, Virchow Hospital,

Humboldt-University Berlin, Germany

\section{References}

1. Daimaru Y, Kido H, Hashimoto H, Enjoli M. Benign schwannoma of the gastrointestinal tract. Hum Pathol 1988; 19: 25764 .

2. Knight WA, Murphy WK, Gaottlieb JA. Neurofibromatosis associated with malignant neurofibromas. Arch Dermatol 1973; 107: $747-50$.

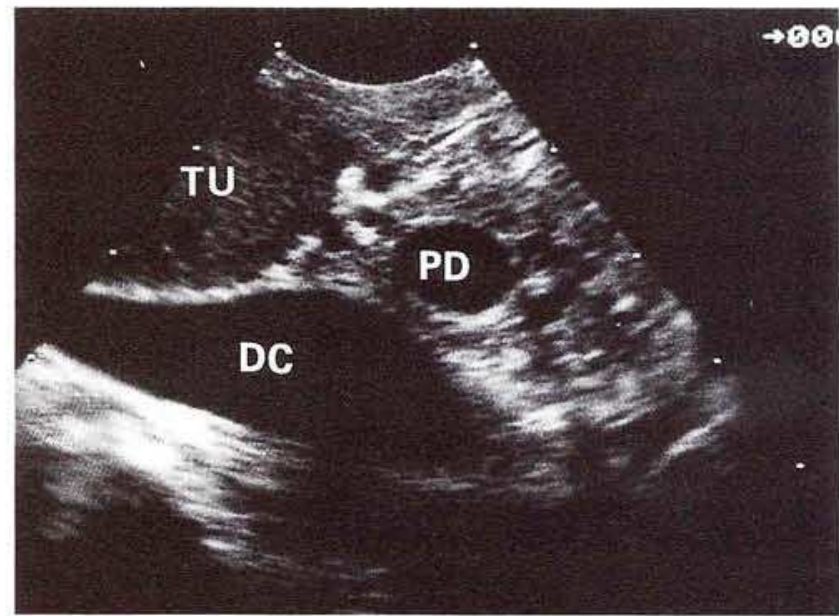

Figure 2: Endosonography: Compression of the common bile duct (DC), caused by an echo-poor tumor (TU). PD = pancreatic duct.

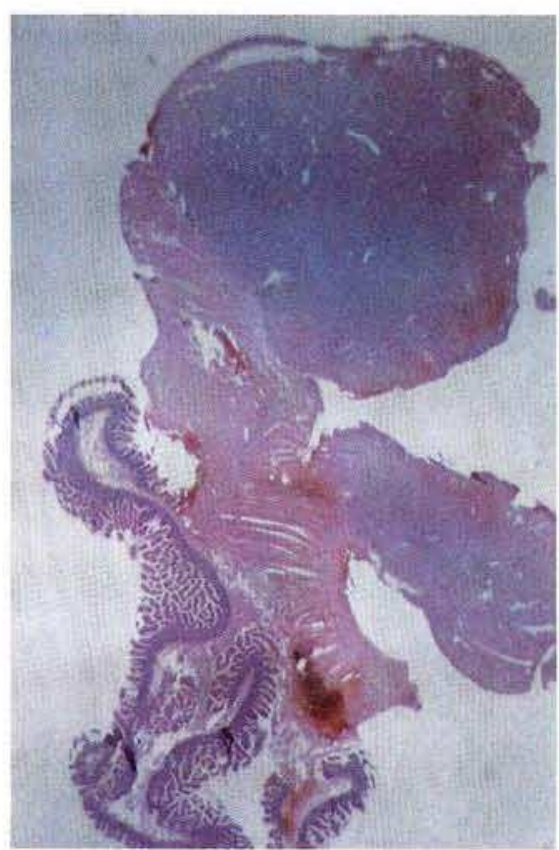

Figure 3: Histological section of the resection specimen, demonstrating a submucosal malignant schwannoma of the duodenum. 
3. Godlewski G, Sawan S, Targhetta P, Pignodel C, Marty Double C, Gaujoux AF. A malignant schwannoma of the jejunum associated with multiple neurofibromas and a primary adenoma of the parathyroid. Ann Gastroenterol Hepatol (Paris) 1989; 25: 13 $-7$.

4. Cohen BH, Rothner AD. Incidence, types and management of cancer in patients with neurofibromatosis. Oncology 1989; 3 (9): $23-30$

5. Awrich AE, Irish E, Vetto M, Fletcher WS. A twenty-five year experience with primary malignant tumors of the small intestine. Surg Gynecol Obstet 1980; 151: 9-13.
Corresponding Author

P. M. Schlag, M.D.

Dept. of Surgery

Robert-Rössle Hospital

Lindenbergweg 80

13122 Berlin

Germany

Fax: +49-30-9417-1404 